\title{
CARACTERIZAÇ̃̃O COMPARATIVA DE ALGUNS FATORES NUTRICIONAIS E ANTINUTRICIONAIS EM FARINHAS DE SOJA E DE TEMPÉ
}

\author{
Maria Angélica C. Fonseca Stein
}

Orientador: Prof. Dr. Rodolpho de Camargo

Dissertaçào apresentada à Escola Superior de Agricultura "Luiz de Queiroz", da Universldade de Sảo Paulo, para obtençào do Título de Mestre em Tecnologia de Alimentos

PIRACICABA

Estado de São Paulo - Brasil

Novembro 1980 
A meu esposo, CARLOS ALBERTo, que por seu incentivo constante em muito contribuiu para a realização deste trabalho, 
A autora expressa seus agradecimentos mais sin ceros às seguintes pessoas e entidades:

Ao Prof. Dr. Rodolpho de Camargo, responsāvel primeiro por nossa iniciação cientifica, pelo apoio e segura orientação demonstrados no decorrer deste trabalho;

A Fundação de Amparo à Pesquisa do Estado de São Paulo, pé 10 auxîlio concedido à partir de 1978, na forma de bolsa de estudos, sem o qual não seria possĩvel a realização deste trabalho;

Ao Instituto de Tecnologia de Alimentos, na pessoa do Dr. Mauro Faber de Freitas Leitão, pelas facilidades concedi das na utilização de seus laboratōrios e pelo fornecimen to dos animais utilizados para a determinação do fator bo ciogênico;

Ao Dr. Arlindo Moreira Salles, pela orientação das anālises do inibidor de tripsina e da digestibilidade "in vitro";

Ao Dr. Iovaldo B. Figueiredo, pela utilização de seu labora tório para anālises diversas;

Ao Prof. Dr. Franco Lajolo e Tulia Filisetti, da Faculdade de Ciēncias Farmacéuticas da USP, pelo planejamento e orientação na determinação do fator bociogēnico;

A Seção de Leguminosas do Instituto Agronōmico de Campinas, pelo fornecimento das amostras de soja; 
Ao Centro de Energia Nuclear na Agricultura, nas pessoas do Prof. Dr. Otto Jesu Crocomo e Dr. Francisco Josē Krug, pe las anālises de aminoācidos e proteinas;

Aos Funcionārios do Departamento de Tecnología Rural da Esco la Superior de Agricultura "Luiz de Queiroz", pela amiza de e pela colaboração prestada.

E a todos que direta ou indiretamente contribuiram para a realização deste trabalho. 
LISTA DE TABELAS ..................... vi

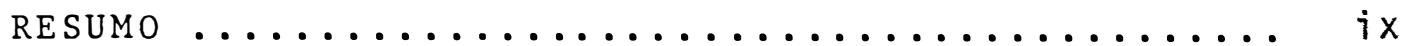

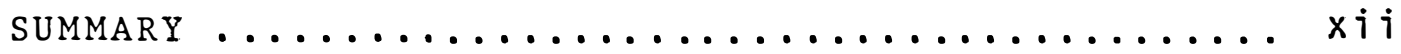

$1-\operatorname{INTRODUÇ\tilde {O}O\ldots \ldots \ldots \ldots \ldots \ldots \ldots \ldots \ldots \ldots \ldots \ldots \ldots \ldots \ldots \ldots \ldots \ldots \ldots \ldots \ldots }$

2 - Revisão de literatura $\ldots \ldots \ldots \ldots \ldots \ldots \ldots \ldots \ldots \ldots \ldots \ldots \ldots \ldots \ldots \ldots \ldots$

2.1 - Valor Nutricional do Tempê ........... 5

2.2 - Fatores Antinutricionais da Soja ........ 8

2.2 .1 - Inibidores de Tripsina ......... 8

2.2.1.1 - Efeitos fisiológicos em animais de laboratório .............. 8

2.2 .1 .2 - Eliminação pelo calor úmido ...... 10

2.2.1.3 - Importância para a nutrição humana. 12

2.2 .2 - "Fator" Bociogênico............ 13

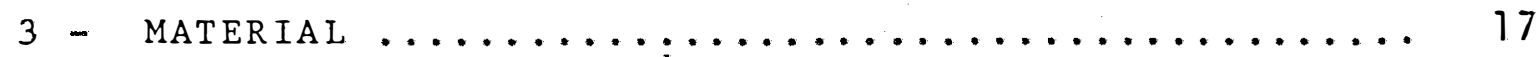

3.1 - Preparo do Material para Armazenamento .... 18

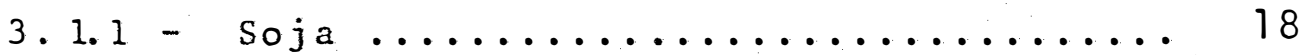

3.1 .2 - Farinha de soja .............. 18

3.1 .3 - Farinha de Tempê ............... 19

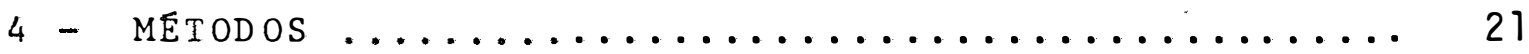

4.1 - Composição Centesimal ............. 21 
$4.1 .1-$ Umidade $\ldots \ldots \ldots \ldots \ldots \ldots \ldots \ldots \ldots \ldots \ldots \ldots$

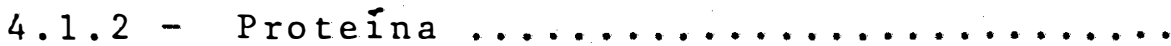

4.1.2.1 - Proteína total pelo método de

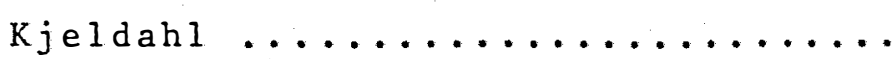

4.1.2.2 - Proteína total pelo método de

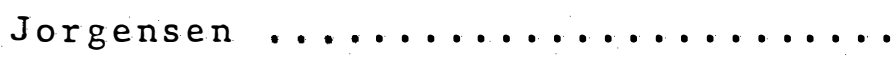

4.1. 2.3 - Proteína solúvel pelo método de Lowry .................... 22

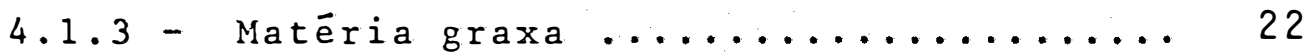

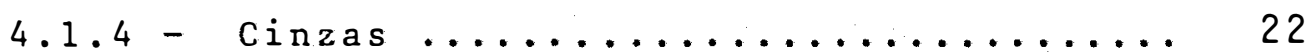

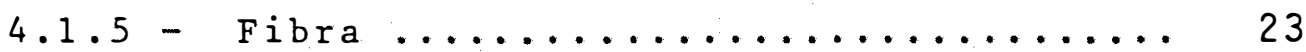

$4.1 .6-$ Carboidratos .................. 23

4.2 - Atividade Ureātica ................ 23

4.3 - Fatores Antinutricionais ............. 23

4.3 .1 - Inibidor de Tripsina ........... 23

4.3 .2 - "Fator" Bociogênico ............ 24

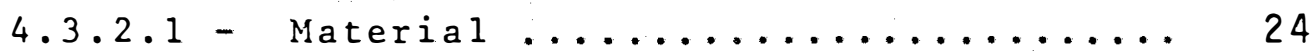

4.3.2.1.1 - Obtenção do extrato de farinha de soja e de farinha de Tempé ... 24

4.3 .2 .1 .2 - Animais ............... 26

4.3 .2 .1 .3 - Iodo radioativo ........... 26

$4.3 .2 .1 .4-$ Equipamento .............. 27

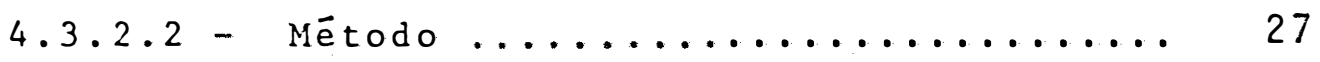

4.3 .2 .2 .1 - Anālise estatística .......... 28 
4.4 - Digestibilidade "in vitro" ........... 28

4.5 - Anälise dos Aminoäcidos ............... 29

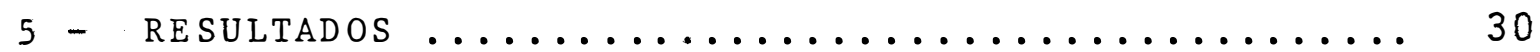

6 - Discussão dos Resultados $\ldots \ldots \ldots \ldots \ldots \ldots$

$7-$ Conclusões $\ldots \ldots \ldots \ldots \ldots \ldots \ldots \ldots \ldots \ldots \ldots \ldots \ldots \ldots \ldots \ldots \ldots \ldots \ldots$

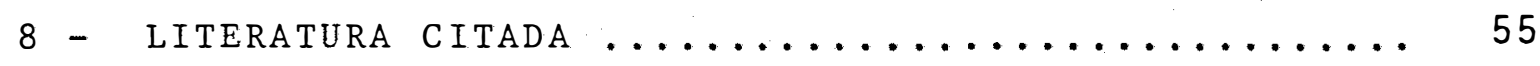


TABELA 1 - Proteina total em soja, farinha de soja

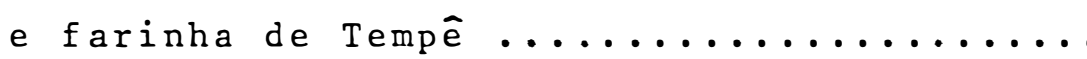

TABELA 2 - Composição centesimal da soja ..........

TABELA 3 - Composição centesimal da farinha de soja..

TABELA 4 - Composição centesimal da farinha de tempê.

TABELA 5 - Atividade ureätica em soja, farinha de so ja e farinha de tempê $\ldots \ldots \ldots \ldots \ldots \ldots \ldots$

TABELA 6 - Determinação da atividade do inibidor de Tripsina utilizando BAPA como substrato ...

TABELA 7 - Medida da radioatividade de glândulas tí

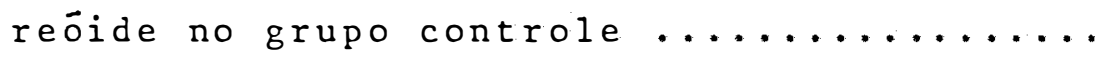

TABELA 8 - Medida da radioatividade de glândulas ti reóide no grupo da farinha de soja, va-

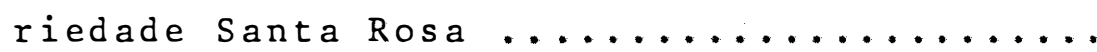

TABELA 9 - Medida da radioatividade de glândulas tí reóide no grupo da farinha de tempê, va-

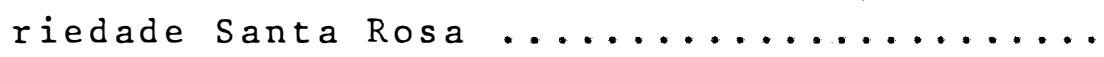

TABELA 10 - Porcentagem de captação por $100 \mathrm{~g}$ de peso de rato, nos grupos controle, farinha de soja e farinha de tempê (Santa. Rosa) ... 
TABELA 11 - Porcentagem média de captação por $100 \mathrm{~g}$

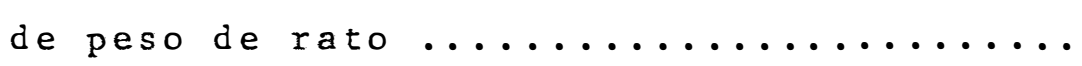

TABELA 12 - Composição em aminoácidos (mg por $100 \mathrm{~g}$ de produto) em farinha de soja, nas variedades Santa Rosa., Viçoja, IAC- 2 e

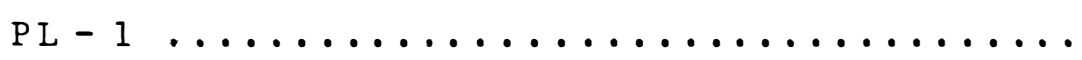

TABELA 13 - Composição em aminoācidos (mg por $100 \mathrm{~g}$ de produto) em farinha de tempê, nas va riedades Santa Rosa, Viçoja, IAC- 2 e

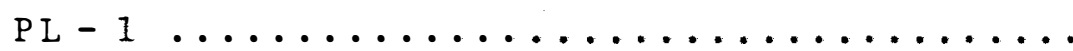

TABELA 14 - Digestibilidade "in vitro" para farinha de soja e de tempê, nas variedades Santa Rosa, Viçoja, IAC- 2 e PL- 1 (\%

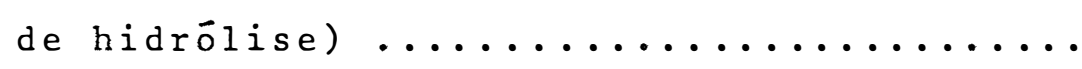

TABELA 15 - Digestibilidade "in vitro" para farinha de soja e de tempê, nás variedades Santa Rosa, Viçoja, IAC- 2 e PL- 1 ( $\mu g$ de $\alpha$-aminoācidos liberados por mg de amostra) $\ldots \ldots \ldots \ldots \ldots \ldots \ldots \ldots \ldots \ldots$

\section{LISTA DE FIGURA}

Pàg.

FIguRA 1 - Extração do "fator" Bociogênico ........ 


\title{
CARACTERIZAGÃO COMPARATIVA DE ALGUNS FATQREES NUTRICIONAIS E ANTINUTRICIONAIS EM EARINHAS DE SOJA E DE TEMPEE
}

\author{
Maria Angélica C. Fonseca Stein \\ Prof, Dr, Rodolpho de Camargo
}

RESUMO

Foram estudadas algumas caracteristicas nutricionais e antinutricionais do Tempē em forma de farinha, comparativamente com a farinha de soja. Utilizou-se quatro variedades de soja (Santa Rosa, Viçoja, IAC-2 e PL-1), relacionadas principalmente com a intensidade atual de cultura no Estado de São Paulo, ou para serem introduzidas na lavoura pau lista.

A composição centesimal da soja e das farinhas foi determinada, bem como a atividade ureática e do inibidor de tripsina.

As farinhas foram analisadas quanto à sua composição em aminoácidos e à digestibilidade "in vitro".

A variedade Santa Rosa teve suas farinhas ensaiadas para a determinação do fator bociogēnico. 
os resultados obtidos sugerem as seguintes con

clusões:

1 - A maceração elimina parte dos sōlidos solūveis da soja, notadamente os carboidratos.

2 - 0 processo de fermentação não altera grandemente a compo sição da farinha de tempé, quando comparada à farinha de soja.

3 - 0 tratamento térmico sofrido pelas farinhas é suficiente para inativar a urease em, no minimo, $94,6 \%$.

4 - As variedades de soja estudadas classificam-se na faixa de "baixa" atividade de inibidor de tripsina, sendo que duas das variedades estudadas, $P L-1$ e Santa Rosa estão abaixo do valor minimo encontrado por KAKADE et ali $(1972)$.

5 - Pelos resultados obtidos com a determinação da atividade do inibidor de tripsina, para as farinhas de soja e de tempé, não foi possĩvel afirmar se durante a fermentação o que ocorre é a liberação dos inibidores de tripsina ter moresistentes ligados (inativos) ou a solubilização dos inibidores de tripsina desnaturados pelo calor ou, ainda, se os fenómenos estão ocorrendo conjuntamente.

6 - Existe um fator presente na farinha de tempé capaz de di minuir a captação de iodo pela glāndula tireoide de ratos, 24 horas apōs sua administração. 
7 - A composição em aminoācidos mostrou-se praticamente sem alterações nos dois produtos estudados.

8 - Embora algumas variedades tenham apresentado maior liberação de aminoācidos na farinha de tempē, a porcentàgem de hidrōlise foi bastante semelhante entre os dois produ tos estudados. 


\title{
COMPARATIVE CHARACTERIZATION OF SOME NUTRITIONAL AND ANTINUTRITIONAL FACTORS PRESEENT IN SOYBEEAN AND TEMPEEH \\ FLOURS
}

\author{
Maria Angélica C, Fonseca Stein
}

Prof, Dr, Rodolpho de Camargo ADV I SOR

SUMMARY

Some nutritional and antinutritional characteristics of Tempeh Flour, comparatively with Soybean Flour, we re studied.

Four soybean varieties were utilized (Santa Ro sa, Viçoja; IAC-2 e $P L-1)$, related to their crop intensity in the State of São Paulo, or in the process of beeing introduced as new varieties.

Chemical composition of soybeans and their flours, as well ureatic activity and soybean trypsin inhibitor activity were determined.

The flours were analysed for their aminoacid composition and "in vitro" digestibility. 
Goitrogenic factor was determined in flours obtained from soybeans of Santa Rosa variety.

The results obtained suggest the following conclusions:

1 - Soaking overnight partially eliminates soybean soluble solids, mainly carbohidrates.

2 - The fermentation process doesn't significantly change the chemical composition of tempeh flour, in comparison with soybean flour.

3 - Heat treatment of all flours was sufficient to inactivate urease to a level of at least $94.6 \%$.

4 - The soybean varieties under investigation are classified as with "low" activity of trypsin inhibitor, occurring that two of the varieties studied, ( $P L-1$ and Santa Rosa) are below the minimum value found by KAKADE et ali $i$ $(7.972)$.

5 - From the results obtained with the determination of the trypsin inhibitor activity, for tempeh and soybean flours, it was not possible to affirm if during the fermentation period what occurs is the 1 iberation of the bounded heat resistant trypsin inhibitors (inactivated) or the solubi lization of the heat denaturated trypsin inhibitor or, if the two phenomena are occurring simultaneously. 
6 - A factor is present in the tempeh flour capable of depres sing iodine caption in rats, 24 hours after its administration.

7 - Aminoacid composition did not show significant alteration in the two products studied.

8 - Although some varieties showed greater aminoacid liberation in the tempeh flour, the percentual hydrolisis was very similar between the two products studied. 


\section{1 - INTRODUCÃO}

A soja (Glycine $\max$ (L.) Merril) tem sido legu minosa amplamente consumida pelos povos orientais há milénios, os quais criaram diferentes maneiras de preparā-la de modo a modificar suas características organolépticas e obter produ tos de melhor palatabilidade em comparação à matéria-prima original.

Com o desenvolvimento da tecnologia a soja tem sido apontada como uma das melhores fontes na solução do problema da necessidade de proteinas do mundo atual.

As estimativas indicam que, atualmente, existem um bilhão e meio de homens, mulheres e crianças que sofrem de desnutrição grave, moderada ou branda e que obviamente, a maio ria dessas pessoas vive nos países em desenvolvimento. Dados recentes de uma pesquisa de cinco anos da "Inter-American Investigation of Mortality in Children" indicaram a desnutrição 
como o mais importante fator contribuinte para a alta taxa de mortalidade infantil na Amērica Latina.

Devido ao efeito sinērgico da combinação entre a desnutrição e infecção, as crianças desnutridas estão mais sujeitas a contrair doenças infecciosas sendo, também, menos capazes de resistir aos efeitos dessas doenças do que as crianças adequadamente nutridas. Porisso, a elevada taxa de mor tal idade infantil causada por doenças infecciosas, nos países em desenvolvimento, constitui um reflexo do estado nutricio nal das mesmas. Na idade escolar, essas crianças afetadas pela subnutrição, irão mostrar sinais de subdesenvolvimento físico e mental.

A longo prazo, os efeitos da desnutrição podem relacionar-se ao desenvolvimento sōcio-econōmico de uma nação. A baixa produtividade, a má qualidade de vida, o aumento dos gastos com saūde e tratamento médico e os poucos retornos dos investimentos educacionais são alguns dos prejuízos enfrentados pelos países assolados pela desnutrição. Assim, por motí vos económicos e humanitārios, a nutrição deve ter alta prioridade nos planos nacionais de desenvolvimento.

värios esforços tem sido feitos no sentido de aumentar o consumo da soja pelo brasileiro. Alimentos orientais, adição em embutidos, juntamente com o desenvolvimento da tecnologia para obtenção do leite de soja são apenas algumas das formas sendo estudadas. 
Hā alguns anos concentrou-se a atenção em produtos orientais de soja, notadamente o tempé. Esse produto, originārio da Indonēsia, de sabor bastante aceito pelos orien tais, pode ser obtido por meio de uma tecnologia simples e a baixo custo.

Estudos preliminares, realizados entre as prin cipais variedades de soja do Estado de São Paulo, compararam as farinhas dessas sojas com farinhas de tempē, obtidas das mesmas variedades da leguminosa, por meio de técnicas apropria das. Assim, foram estudadas variedades de soja e respectivas farinhas para composição centesimal, presença de aflatoxinas, valor biológico e anālise sensorial, entre outras. Os resultados foram por demais estimulantes, de modo a conduzir-nos a estudos mais detalhados das farinhas obtidas.

Dessa maneira a autora propõe - se no presente trabalho a estudar algumas caracteristicas do tempé, em for ma de farinha, constituindo-se em objetivos principais a deter minação da composição centesimal das farinhas de tempé em com paração com as farinhas de soja; dos fatores antinutricionais (antitrīpticos e bociogēnico) ; da atividade ureática; do efeito do processamento no teor de aminoácidos das farinhas; e da digestibilidade "in vitro".

Assim, cré-se atingir um estudo abrangente pa ra as principais variedades de soja cultivadas no Estado de 
São Paulo, o que, espera-se, contribuirá para a introdução de novas alternativas que possam minorar o problema da desnutrição protéica em nosso paîs. 


\section{2 - REVISÃO DE LITERATURA}

2.1 - Valor nutricional do Tempé

o valor nutricional do tempé parece estar inti mamente relacionado ao seu método de preparo. A maceração da soja, cozimento, tempo e temperatura de fermentação são passos importantes a serem controlados de modo a se obter um produto final de alto valor alimentício.

HESSELTINE et arii (1963) estudando problemas pertinentes à fermentação observaram que o fungo utilizado pa ra a fermentação do tempé, sob certas condiçōes, é inibido, dando consequentemente uma fermentação muito pobre e um produ to final muito ruim. Os autores concluiram pela existéncia de uma substāncia inibidora do fungo, que é liberada quando os grãos de soja são hidratados em pouco volume de água; quando 
a prōpria āgua de hidratação, mesmo em volumes maiores é usada no cozimento ; ou quando pouca àgua, embora fresca è usada no cozimento.

HACKLER et alii (1964) estudar̉am a utilização da proteina do tempé através de ensaios com ratos em idade de aleitamento. Os autores concluiram que não houve melhora na eficiéncia protéica e nem no crescimento de ratos, em relação à soja não fermentada; e que a aceitação da dieta contendo tempé diminuiu a cada aumento de 12 horas no tempo de fermentação, o qual variou de zero a 72 horas. Os autores f $\underline{i}$ zeram o cozimento da soja na prōpria āgua de maceração, e o tempo de fermentação foi muito superior ao necessārio (18-22 horas), o que poderia explicar os resultados pouco animadores obtidos.

MURATA et alii (1967) realizaram estudos sobre o valor nutricional do tempé, encontrando para o mesmo valores superiores de aminoācidos livres, vitamina $B_{6}$, riboflavina, àcido nicotínico e àcido pantoténico, quando comparado à soja não fermentada. Os teores de fibra e proteina foram semelhan tes para ambos produtos e houve uma ligeira diminuição no con teūdo de matéria graxa no tempé. Nesse experimento não foram realizados ensaios biológicos.

WANG et alii (1968) estudaram o efeito da fermentação sobre o valor nutricional do trigo, da soja e de uma mistura de trigo e soja (1: 1). Observaram que o processo de 
fermentação não afetou grandemente a composição em aminoācidos do trigo e soja, aumentando apenas levemente a quantidade de proteína nos produtos estudados. Os autores encontraram que houve diferença significativa $(P<0,05)$ no coeficiente de eficācia proteica entre o trigo não fermentado e o que sofreu fermentação, bem como entre a mistura trigo-soja fermentada e não fermentada, sendo que os produtos fermentados foram sempre os melhores. Não houve diferença significativa entre a mistura trigo-soja fermentada e o padrão caseína.

CAMARGO (1969) estudou quarenta e trēs culturas de fungos, compreendidas entre dois gēneros e oito espécies, ensaiadas quanto à sua atividade proteolitica, para a fermentação do tempé, concluindo que o fungo de maior atividade foi - Rhizopus oligosporus NRRL 2710 , o que confirma o resultado encontrado por outros autores. Utilizando essa cultura pa ra o preparo do tempé e sua farinha,o autor observou que para duas das cinco variedades de soja estudadas ( $\dot{L}-1556$ e Araçatuba) não houve diferença significativa $(P<0,05)$ em relação ao PER do padrão caseina.

$\mathrm{Na}$ década de 70 o interesse no estudo do valor nutricional da soja, fermentada ou não, medido apenas pelo teor proteíco e avaliação biológica parece decrescer, e ceder lugar a estudos cada vez mais completos, que procuram relacio nar fatores antinutricionais à diminuição do valor como alimento, da soja e seus produtos. 


\section{2 - Fatores Antinutricionais da Soja}

\subsection{1:- INIBIDORES DE TRIPSINA}

2.2.1.1 - Efeitos fisiológicos em animais de laboratório Numerosos experimentos com galinhas e ratos tem demonstrado que os inibidores de tripsina presentes na soja crua interferem no crescimento desses animais, inibindo-o, e produzem hipertrofia pancreática, o que parece ser uma respos ta adaptativa a aumento da necessidade da referida enzima (HAINES e LYMAN, 1961 ; RACKIS, 1965 ; GERTLER et alii, 1967).

A farinha de soja crua, integral e desengordurada, inibe o crescimento, baixa a energia metabolizāvel e a absorção de gordura, reduz a digestibilidade de proteĩna, cau sa hipertrofia pancreática e reduz a disponibilidade de amino ácidos, vitaminas e minerais. Quase todos esses efeitos estão interrelacionados e representam antes uma incapacidade do an $\underline{i}$ mal em utilizar completamente esses nutrientes essenciais do que uma resposta a substancias tóxicas.

RACKIS (1974) apresenta uma revisão bastante completa, abordando os principais fatores biológicos e fisiológicos presentes na soja, inclusive os efeitos inibitórios so bre o crescimento em diversos animais (cão, boi, porco, etc.), bem como sobre o tamanho e a secreção enzímica do pāncreas. 
A inibição de crescimento em pintinhos isentos de germes ("germ-free") alimentados com soja crua é considera velmente menor do que em pintinhos convencionais. A microflo ra parece intensificar as propriedades inibidoras de cresci mento da soja crua. 0 modo de interação entre a microflora e os constituintes dietārios no produto crū é desconhecido. En tretanto, os antibiōticos tem um efeito benéfico no valor nutritivo da soja crua, embora não na mesma extensão do trata mento pelo calor úmido. A hipertrofia pancreātica ocorre tan to nos pintinhos convencionais como nos livres de germes (COA TES et alii, 1970).

A criação de variedades de soja geneticamente deficientes em fatores antinutricionais não parece promissora. KAKADE et alii (1972) encontraram uma larga faixa de variação na atividade do inibidor de tripsina e das hemaglutininas em cento e oito variedades e linhagens experimentais de soja. Os valores nutritivos foram aumentados de 61 a $180 \%$ após auto clavagem. A qualidade da proteina foi avaliada em termos de PER, o qual variou de 0,7 a 1,75 , comparados a um valor de ca seina de 2,5. Apesar da evidēncia que implica inibidores de tripsina e fitohemaglutininas como fatores que contribuem para o pobre valor nutritivo da soja crua, nenhuma relação ficou evidenciada nesses estudos. Tendo em vista a falta de correla ção entre a atividade do inibidor de tripsina e PER, o fato de haver um grau de correlação significativo entre o peso do pan crea e PER causou surpresa, desde que é geralmente aceito que 
que os inibidores de tripsina são os principais responsáveis pela hipertrofia pancreática e pobre crescimento de animais a 1 imentados com soja (GARLICH e NESHEIM, 1966 ; SAMBETH et alii , $1967)$.

Uma possivel explicação seria de que o método utilizado para se medir a atividade antitríptica "in vitro" não reflete o conteúdo real de inibidor de tripsina da soja. Mas não se pode excluir a possibilidade de haver um fator totalmente não relacionado e, não obstante, capaz de causar hipertrofia pancreática e inibição de crescimento. Não houve correlação também entre o PER e o conteúdo de aminoācidos suI furados totais.

2.2.1.2 - Eliminação pelo calor ūmido

Os produtos de soja devem receber, necessariamente, tratamento por calor úmido, afim de que possam ter seu valor nutritivo aumentado. A taxa de melhora no valor nutritivo depende da temperatura, duração do aquecimento e condi ções de umidade.

A maioria dos pesquisadores acreditam que a mā xima eficiēncia protéica é conseguida por autoclavagem a 15 $1 \mathrm{~b} / \mathrm{pol}^{2}\left(1,05 \mathrm{kgf} / \mathrm{cm}^{2}\right)$ de pressão, por não mais de trinta minutos (KLOSE et alii, 1948; BORCHERS et alii, 1948). 
Com apenas 50 a $60 \%$ de destruição da atividade do inibidor de tripsina ocorre hipertrofia pancreática. A des truição da atividade de hemaglutininas é paralela à mostrada pelo inibidor de tripsina (LIENER, 1955).

SMITH et alii (1964) encontraram que apenas 10 a 15 minutos de aquecimento por vapor fluente resultou um PER máximo $(2,50)$.

O tamanho das particulas e a umidade inicial da soja são os maiores fatores influenciando a velocidade de coc ção, a inativação do inibidor de tripsina e o subsequente aumento no valor nutritivo. Com o grão de soja inteiro a maceração antes do tratamento térmico acelera grandemente a taxa de inativação do inibidor de tripsina (RACKIS, 1966 ; ALBRECHT et alii, 1966).

Um dado interessante com respeito ao valor nutritivo da soja é que não é necessārio destruir toda a atividade do inibidor de tripsina para se obter um valor de PER mä ximo.

Segundo RACKIS (1974) o valor māximo de PER é conseguido quando $79 \%$ da atividade do inibidor de tripsina é destruida. Esses resultados foram similares quando os valores de peso corporal e digestibilidade serviram como indices de qualidade da proteina. 
2.2.1.3 - Importāncia para a nutrição humana

os inibidores enzímicos podem agir "in vivo"

de diversas maneiras, quais sejam: a) afetando a ligação e transformação do substrato para produto final; b) tornando o substrato não disponivel; c) interferindo com a biossintese da enzima; d) aumentando a taxa de renovação da enzima;

e) afetando um hormōnio, o qual por sua vez afetarā ao nīvel da atividade enzimica. O primeiro tipo tem sido o mais frequentemente descrito em alimentos. Soja, feijões de lima (Phaseolus Zinensis), ervilhas e batatas tem sido as principais plantas estudadas com relação à inibição de tripsina. Os ini bidores de tripsina são, provavelmente, os mais amplamente dis tribuidos entre os inibidores de enzimas proteoliticas.

Em estudo preliminar, BUCK et alii (1962) mostraram que, enquanto o inibidor de tripsina da soja inibiu tripsina bovina, suina, ovina e humana, o ovomucoide de galinha inibiu a tripsina apenas das trés primeiras espécies, não inibindo a tripsina humana.

Em estudo mais detalhado FEENEY et alii (1969) encontraram que a tripsina humana foi fortemente inibida por très inibidores aparentemente não relacionados, provenientes do feijão de lima (Fhaseozus Iinensis) do colostro bovino e do inibidor pancreático KUNITZ, ao passo que os inibidores da soja, o inibidor do feijão "kidney" (Fhaseolus vulgaris) e ou tros, inibiram-na em menor grau. Entretanto, a tripsina huma na não foi inibida por inibidor pancreático bovino e suíno, 
por inibidor de batata, de ovo de galinha e outros. Muitos desses inibidores provocaram forte inibição da tripsina bovina.

No mesmo ano TRAVIS e ROBERTS (1969) constaitaram que o inibidor de tripsina da soja não inibiu a tripsina humana. A declaração desses autores provocou imediatamente es peculações de que a atividade do inibidor de tripsina da soja crua teria pouco ou nenhum significado para a nutrição humana.

Mais tarde, COAN e TRAVIS (1973) isolaram duas formas de tripsina do pāncreas humano. A forma aniōnica é com pletamente inibida pelo inibidor de tripsina a uma relação mo 1 ar de $1: 1$, enquanto que a forma catiónica é inibida em ape nas $20 \%$.

0 único experimento realizado com humanos ind $\underline{i}$ ca que a farinha de soja crua pode manter um balanço de nitro gēnio positivo, mas não tão eficientemente quanto a farinha de soja autoclavada (LEWIS e TAYLOR, 1947).

\section{2 .2 - "FATOR" BOCiOGËnico}

MCCARRISON (1933) foi o primeiro a relatar a $\underline{a}$ ção bociogēnica da soja.

Estudos nos mostram que inúmeros pesquisadores atribuem vārias causas aos diferentes efeitos causados pela so 
ja sobre a glàndula tireóide.

Alguns como SHARPLESS et alii (1939); WILGUS et alii (1941) e HALVERSON et alii (1949), observaram a presença de bócio em ratos e galinhas alimentados com soja crua, o que atribuem à deficiēncia de iodo na dieta. Segundo os au tores essa propriedade era inibida, parcialmente, pelo tratamento térmico da soja ou, totalmente, pela administração de quantidades elevadas de iodo.

Segundo SHARPLESS et alii (1939) a propriedade bociogēnica da soja crua podia ser parcialmente eliminada por tratamento com èter ou acetona. Os demais autores citados en contraram resultado discordante, segundo os quais o tratamento com solventes orgānicos como acetona, etanol, éter ou cloroförmio não eliminava o "fator" bociogēnico da soja crua.

Posteriormente, BLOCK et alii (1961), observaram que havia uma redução na capacidade bociogēnica da soja crua quando a mesma era desengordurada.

VAN WYK (1959) observou efeitos bociogēnicos em crianças alérgicas alimentadas com leite de soja, verificando que havia uma diminuição na retenção de iodo marcado. Esses efeitos puderam ser observados também em dois, de um grupo de quatorze adultos alimentados com leite de soja por um periodo de cinco dias, sugerindo que ocorre interferéncia com a sinte se de hormōnios tireoidianos de acordo com a susceptibilidade individual. 
Efeito conträrio, isto é, hipertireoidismo,foi observado em ratos (VANMIDDLESWORTH, 1957 ; BECK, 1958), e em crianças (HYDOWITZ, 1960 ; SHEPARD et alii, 1969 ; PINCHERA et alii , 1965), medidó por um aumento na captação de iodo rá dioativo.

NORDSIEK (1962) realizando estudo em ratos al $\underline{i}$ mentados com rações contendo de 35 a $60 \%$ de soja crua obser vou que os animais apresentavam um aumento de peso da gländula tireóide. Adicionando-se caseĩna à ração esse efeito era eliminado. O autor sugere que esse efeito bociogénico pode ria estar relacionado com a presença de antitripsina.

KONIJN (1972) procurou extrair e caracterizar a atividade do "fator" bociogènico. Encontrou que o mesmo é solūvel a pH4,2, em dois volumes de acetona ou em ācido trí cloroacético a $10 \%$, e insolūvel em acetona a $90 \%$, etanol a $90 \%$ e em éter etīlico. Não é precipitado por sulfato de amónia e resiste à digestão pancreática e à ebulição por duas ho ras, mas, aparentemente, é destruído por autoclavagem. Quan do adicionado à dieta de ratos diminui a captação de iodo pela glàndula tireóide.

Em trabalho posterior, KONIJN et alii (1973) conseguiram uma purificação parcial do "fator" bociogēnico da soja, caracterizando-o como sendo um composto de baixo peso molecular, provavelmente um oligopeptideo composto de dois ou très aminoācidos ou um glicopeptídeo constituído de um ou dois aminoácidos e uma molécula de açūcar. Os resultados mos 
tram uma inibição na captação de iodo e um decréscimo da sua incorporação à moléculas orgānicas na glāndula. Quando houve exposição "in vitro" da glāndula ao agente depressor, verificou-se uma menor incorporação de iodo radioativo na forma de diiodotirosina (DIT) e a relação tetraiodotirosina/tirosina, tornou-se maior.

Recentemente, FILISETTI (1977) constatou a existēncia, na soja autoclavada, de um fator capaz de diminuir, entre 6 e 24 horas após sua administração, a captação de iodo pela tireóide de ratos; esse fator não foi, porém, encontrado na soja crua. O mesmo fator existe também em produtos comerciais, como: concentrado protéico de soja, farinha de soja tostada e leite de soja, e é resistente ao tratamento térmico à $112^{\circ} \mathrm{C}$ por sessenta minutos. Em ensaios semicrónicos com animais o fator pode provocar tanto aumento como diminuição da captação, dependendo do tempo de ação.

Como se pode observar, através da revisão de literatura, alguns autores afirmam que a soja causa hiperti reoidismo, outros, ao contrārio, que a mesma causa hipotireoi dismo, e outros ainda simplesmente negam qualquer ação bociogènica da soja (SOCOLOW e SUSUKI, 1964). 
O material utilizado para a execução do presen te trabalho constou de amostras de soja da safra de 1977, for necidas pela Secção de Leguminosas do Instituto Agronōmico de Campinas, da Secretaria de Agricultura do Estado de São Pau10 .

Foram utilizadas quatro variedades de soja, re lacionadas principalmente com a intensidade atual de cultivo no Estado de São Paulo, ou para serem introduzidas na lavoura paulista sob o controle da entidade acima mencionada.

As variedades de soja estudadas foram:

1 - Variedade São Rosa

2 - Variedade Viçoja

3 - Variedade IAC-2

4 - Variedade PL-1 


\section{1 - Preparo do Material para Armazenamento}

$$
3.1 .1-\text { SOJA }
$$

Para todas as variedades de soja obedeceu-se à mesma técnica de preparo e armazenamento. Para isto foram os grãos de soja submetidos a tratamento térmico em estufa com circulação de ar $\left(60^{\circ} \mathrm{C}\right)$ por duas horas de modo a permitir o descascamento, desintegrados em moinho e passados através de despolpador de café para completa remoção da casca. Em segui da procedeu-se à moagem, pulverização e acondicionamento em vidros, os quais foram guardados em geladeira.

\section{1 .2 - FARINHA DE SOJA}

A soja foi tratada termicamente em estufa com circulação de ar $\left(60^{\circ} \mathrm{C}\right)$, também por duas horas, desintegrada em moinho e passada através de despolpador de café para completa remoção da casca, macerada em excesso de água por uma noite, após o que foi lavada em abundāncia de āgua. A seguir foi cozida em ebulição por 30 minutos (a água foi adicionada em quantidade de cinco vezes o peso inicial da soja). Após o cozimento foi escorrida e levada novamente à estufa $\left(60^{\circ} \mathrm{C}\right)$ atē que estivesse com 3 a $7 \%$ de umidade. Em seguida foi moida, pulverizada, acondicionada em vidros com tampa de rosca, e guardada em geladeira. 


\section{1 .3 - FARINHA DE TEMPË}

Por tratar-se de técnica pouco difundida, dare mos sua descrição detalhada.

o tempè e sua farinha foram obtidos como des crito por CAMARGO (1969):

a - A soja fragmentada e livre de casca é lavada em āgua cor rente e, em seguida, macerada por uma noite, à temperatú ra ambiente, em volume de āgua de trēs a cinco vezes o seu prōprio.

b - 0 excesso de āgua de maceração é eliminado e os grãos de soja novamente lavados em àgua corrente.

c - Adiciona-se novamente água fresca em excesso e leva-se ao cozimento, contando-se trinta minutos após o início da ebulição.

d - Drena-se a āgua de cozimento, recebendo-se a soja em toa lhas (esterilizadas em autoclave por vinte minutos a 1 at.).

e - Deixa-se os grãos de soja envoltos nessas toalhas a té que atinjam a temperatura ambiente, ponto em que terão perdi do o excesso de umidade prejudicial à fermentação.

$f$ - Após o resfriamento, recolhe-se os grãos de soja em reci piente apropriado (aço inoxidāvel esterilizado), e proce de-se à inoculação com esporos do agente de fermentação (Rhizopus oligosporus NRRL 2710), cuidando-se que a cultura seja jovem, isto é, tenha não mais que $6-8$ dias de idade. 
g - Terminada a inoculação, os grãos de soja são colocados nos recipientes de fermentação (placas de Petri), sendo dispostos de forma a deixar um mínimo de espaço vazio entre a sua massa e a tampa, pois se isso não for observado haverá ar em excesso e o fungo tenderá a esporular,

- o que não é desejāvel.

h - O material inoculado é imediatamente conduzido à incubação a $31^{\circ} \mathrm{C}$. O tempo de fermentação foi de 18 a 22 horas.

i - Após esse período hā desenvolvimento abundante de micélio branco, compactando a massa toda como um bolo, o que dará a fermentação como concluĩda. Um pouco de esporula ção pode eventualmente ocorrer nos bordos da massa fermentada, o que é considerado normal.

j - Terminada a fermentação, o Tempē é cortado em pedaços e levado à estufa a $60^{\circ} \mathrm{C}$ para secar (até 3 a $7 \%$ de umida de), sendo depois moido e pulverizado, obtendo-se assim a farinha, a qual foi, em seguida, acondicionada em vidros e guardada em geladeira. 


\section{4 - MËTODOS}

4.1 - Composigão Centesimal

4.1 .1 - UMIDADE

A umidade das amostras foi determinada de acordo com O A.O.A.C. (1970).

4.1 .2 - Proteina

A determinação de proteina foi efetuada por três diferentes métodos, como segue:

4.1.2.1 - Proteina total pelo Método de Kjeldahl As determinações de proteina total (nitrogênio 
$x$ 6,25) foram feitas de acordo com o método descrito pel.o A.O.A.C. (1970).

4.1.2.2 - Proteína total pelo Método de Jorgensen o método é uma modificação do Método Industrial "Technicon" No 218-72A (JORGENSEN, s./d.).

4.1.2.3 - Proteina solūvel pelo Método de Lowry Os resultados obtidos através desse método (LOW BY et azii, 1951) foram utilizados para os cālculos da digestibilidade "in vitro".

4.1 .3 - Matéria graxa

A determinação de matéria graxa foi feita de acordo com O A.O.A.C. (1970).

$$
4.1 .4-\text { CINZAS }
$$

o teor de cinzas foi obtido pelo método do A.A.C.C. (1969), modificado pelo Setor de Panificação do ITAL (VITTI, 1975), comunicação pessoal. 


\section{$4.1 .5-$ FIBRA CRUA}

A determinação de fibra crua foi feita no ITAL, de acordo com o método de DIEMAIR (1963).

4.1 .6 - CARBOIDRATOS

o teor de carboidratos foi calculado com base na diferença entre a soma dos teores de proteina, matéria gra $x a$, cinzas, fibra e o valor 100.

4,2 - Atividade UREÁTica

A atividade ureática foi determinada segundo o método de SMITH et alii (1956).

4,3 - Fatores Antinutricionais

$4.3,1$ - INIBIDOR DE TRIPSINA

Os testes para inibição de tripsina foram rea lizados no Instituto de Tecnologia de Alimentos, de acordo com o método de KAKADE et alii (1974). 


\section{3 .2 - "FATOR" BOCIOGËNICO}

Por tratar-se de método menos comumente utilizado daremos sua descrição detalhada.

A determinação do fator bociogénico foi realizada de acordo com KONIJN et azii (1972), modificada segundo FILISETTI (1977), como segue:

4.3.2.1 - Material

4.3.2.1.1 - Obtenção do extrato de farinha de soja e de farinha de tempé

As farinhas de soja e de tempē previamente obtidas, foram desengorduradas utilizando-se éter de petrōleo e extrator Soxhlet. A seguir foram tratadas como sugerido por KONIJN et alii (1972), com as modificações descritas abaixo e esquematizadas na Figura 1.

- $100 \mathrm{~g}$ de Farinha de Soja Desengordurada (FSD) e de Farinha de Tempé Desengordurada (FTD) foram tratadas com $750 \mathrm{ml}$ de àgua destilada, acidificadas com HCl $6 \mathrm{~N}$ até $\mathrm{pH}$ 4,2 (ponto isoelétrico das proteinnas da soja), submetidas à agitação por uma hora, sendo, a seguir, a suspensão filtrada. o precipitado foi reextraído com $250 \mathrm{ml}$ de água destilada, da mesma forma, e o sobrenadante resultante acrescentado ao anterior. 
100

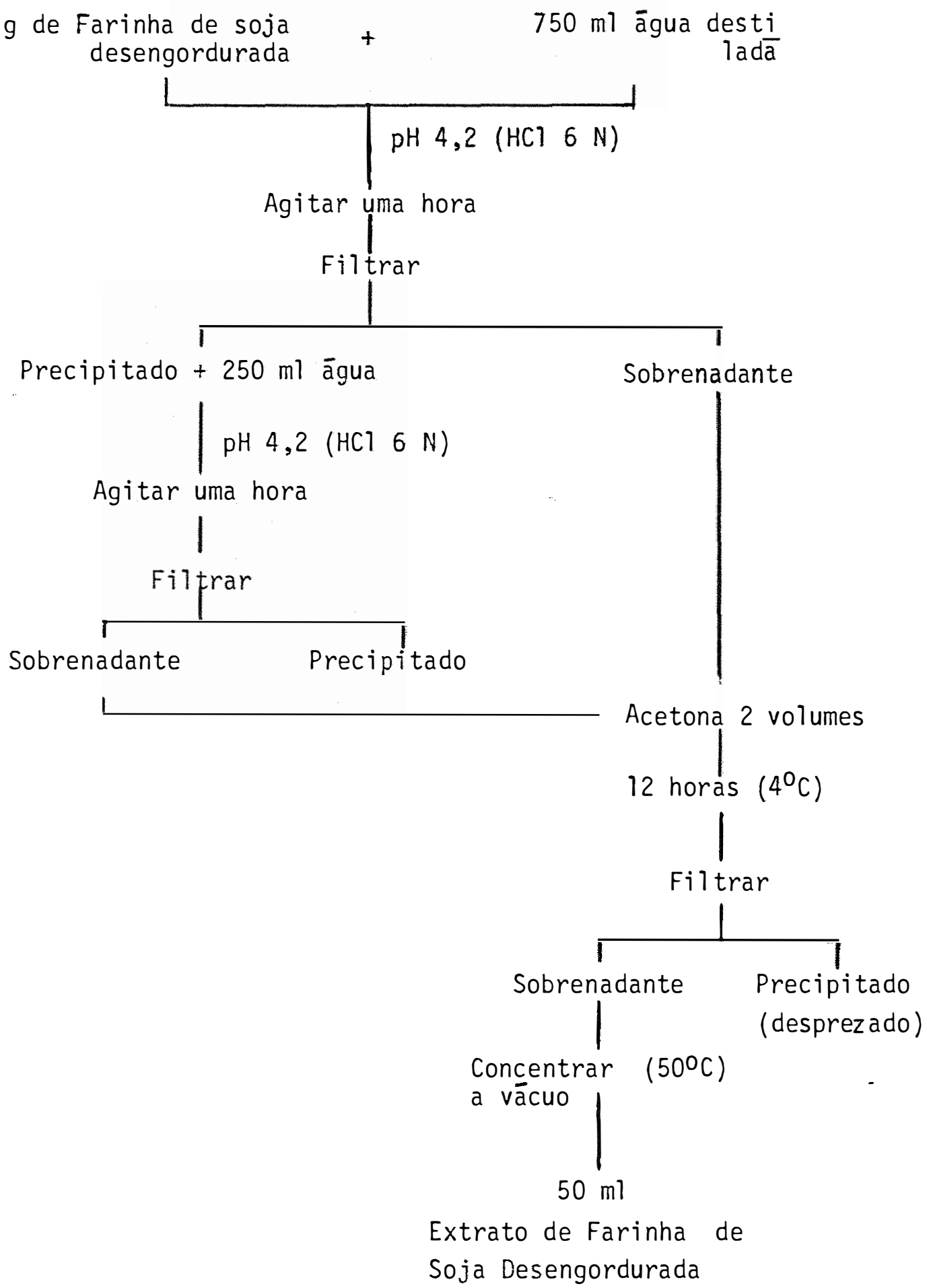

FIGURA 1 - Extração do "Fator" Bociogēnico 
o sobrenadante foi tratado com acetona na proporção de dois volumes de acetona para um volume de sobrenadante. Após repou so a $4{ }^{\circ} \mathrm{C}$ por uma noite, o extrato cetōnico foi filtrado, e o filtrado concentrado em evaporador rotatōrio à vácuo $\left(50^{\circ} \mathrm{C}\right)$ a té volume de $50 \mathrm{ml}$ obtendo-se, assim, o Extrato de Farinha de Soja Desengordurada (EFS) e o Extrato de Farinha de Tempé Desengordurada (EFT).

\subsubsection{2-Animais}

Utilizou-se ratos (Rattus norvergicus, var. a binus) obtidos de colōnias mantidas no biotērio do Instituto de Tecnologia de Alimentos e alimentados com ração padrão (co mercial) do mesmo. Durante a experiéncia foram alojados em gaiolas individuais, no biotério da Faculdade de Ciência Farmacéuticas da USP, recebendo água "ad libitum" e ração comer cial padrão.

4.3.2.1.3 - Iodo radioativo

$$
\text { Usou-se iodeto de sódio (Na }{ }^{131} \mathrm{I} \text { ) dissolvido em }
$$
solução fisiológica e isento de carregador e de redutor. 


\subsubsection{4 - Equipamento}

Além do equipamento convencional de laborató rio, utilizou-se para as contagens um detector de cintilação, com cristal de poço de iodeto de sódio, ativado com tālio NaI (Tl), e contador modelo "Ultra Scaler II" (Nuclear Chicago).

\subsubsection{2 - Método}

- $2 \mathrm{ml}$ do extrato anteriormente obtido, correspon dentes à ingestão de $4 \mathrm{~g}$ de farinha de soja ou de farinha de tempé desengorduradas foram administradas através de sonda gās trica a grupos de ratos mantidos em jejum por 12 horas e alojados em gaiolas individuais. Os ratos do grupo controle recebiam, da mesma forma, 2 ml de solução fisiológica. Decorrí da uma hora, injetava-se por via intraperitoneal cerca de $5 \mathrm{HCi}^{131} \mathrm{I} / 100 \mathrm{~g}$ de peso de rato, num volume de $1 \mathrm{ml}$. Após a administração do radioiodo os animais eram alimentados com ração normal do biotério. Decorridas 24 horas os animais foram sacrificados por inalação de éter, as tireóides com a trá queia removidas, lavadas com solução fisiológica e sua radioatividade medida. 
o efeito do fator bociogēnico em estudo foi avaliado calculando-se a porcentagem de captação/ $100 \mathrm{~g}$ de peso do animal. A porcentagem de captação foi calculada divi dindo-se o nümero de contagens obitidas com a tireóide por aquelas obtidas contando-se, nas mesmas condições, $1 \mathrm{ml}$ de uma diluição conveniente de solução padrão injetada nos animais e multiplicando-se a razão por 100. Em todos os casos as con tagens foram superiores a 10.000 para manter-se o erro estatís tico de contagem inferior a $1 \%$.

\subsubsection{1 - Anālise estatística}

Utilizou-se o teste "t" de Student, para compa ração entre duas médias (SPIEGEL, 1967).

4.4 - Digestibilidade "In Vitro"

A digestibilidade "in vitro" foi estimada de a cordo com o método de AKESON e STAHMANN (1964), e os aminogrú pos determinados segundo FIELDS (1972). 
4.5 - AnÁlise dos Aminoācidos

Os aminoācidos foram determinados quantitativa mente pela reação com nihidrina, em analisador de troca iōnica, modelo "Beckman $120 \mathrm{C"}$, do Centro de Energia Nuclear na Agricultura (CENA), em Piracicaba, SP. 
5 - RESULTADOS

os resultados obtidos encontram-se inscritos nas Tabelas de 1 a 15 . 


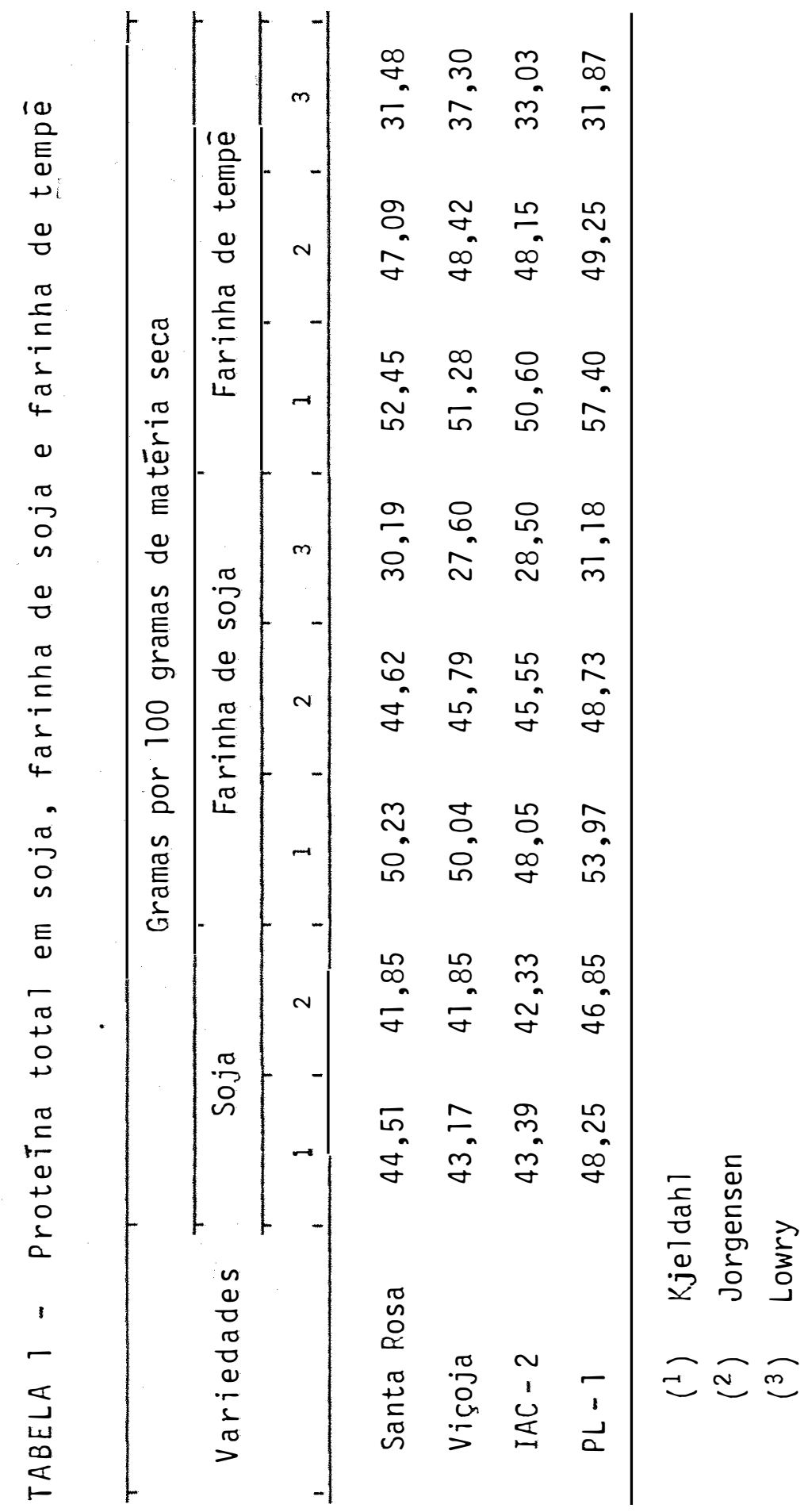


TABELA 2 - Composição centesimal da soja

\begin{tabular}{llcccc}
\hline \multirow{2}{*}{ Variedades } & \multicolumn{5}{c}{ Gramas por 100 gramas de matéria seca } \\
\cline { 2 - 6 } & Proteina & $\begin{array}{c}\text { Matéria } \\
\text { graxa }\end{array}$ & Cinzas & Fibra & $\begin{array}{l}\text { Carboi- } \\
\text { dratos }\end{array}$ \\
\hline Santa Rosa & 41,85 & 24,54 & 3,35 & 2,71 & 27,55 \\
Viçoja & 41,85 & 24,34 & 3,22 & 3,62 & 26,97 \\
IAC-2 & 42,33 & 23,77 & 3,38 & 2,75 & 27,77 \\
PL - 1 & 46,85 & 21,86 & 3,31 & 2,40 & 25,60 \\
\hline
\end{tabular}

TABELA 3 - Composição centesimal da farinha de soja

\begin{tabular}{lccccc}
\hline \multirow{2}{*}{ Variedades } & \multicolumn{5}{c}{ Gramas por 100 gramas de matéria seca } \\
\cline { 2 - 6 } & Proteina & $\begin{array}{c}\text { Matēria } \\
\text { graxa }\end{array}$ & Cinzas ${ }^{\prime}$ Fibra & $\begin{array}{c}\text { Carboi- } \\
\text { dratos }\end{array}$ \\
\hline Santa Rosa & 44,62 & 30,97 & 3,36 & 3,68 & 17,37 \\
Viçoja & 45,79 & 29,61 & 3,19 & 4,05 & 17,36 \\
IAC - 2 & 45,55 & 29,67 & 4,02 & 3,48 & 17,28 \\
PL - 1 & 48,73 & 27,70 & 3,88 & 3,36 & 16,33 \\
\hline
\end{tabular}


TABELA 4 - Composição centesimal da farinha de tempē

\begin{tabular}{llcccc}
\hline \multirow{2}{*}{ Variedades } & \multicolumn{5}{c}{ Gramas por 100 gramas de matéria seca } \\
\cline { 2 - 6 } & Proteina & $\begin{array}{c}\text { Matēria } \\
\text { graxa }\end{array}$ & Cinzas & Fibra & $\begin{array}{l}\text { Carboi- } \\
\text { dratos }\end{array}$ \\
\hline Santa Rosa & 47,09 & 26,94 & 3,36 & 3,99 & 18,62 \\
Viçoja & 48,42 & 28,21 & 3,50 & 3,96 & 15,91 \\
IAC - 2 & 48,15 & 26,62 & 3,53 & 3,41 & 18,29 \\
PL - 1 & 49,25 & 24,23 & 3,34 & 3,87 & 19,31 \\
\hline
\end{tabular}

TABELA 5 - Atividade ureātica em soja, farinha de soja e fá rinha de tempé em variações de unidades de $\mathrm{pH}$

\begin{tabular}{|c|c|c|c|}
\hline \multirow{2}{*}{ Variedades } & \multicolumn{3}{|c|}{ Atividade ureātica } \\
\hline & Soja & $\begin{array}{l}\text { Farinha } \\
\text { de soja }\end{array}$ & $\begin{array}{l}\text { Farinha } \\
\text { de tempé }\end{array}$ \\
\hline Santa Rosa & 2,00 & 0,05 & -.. \\
\hline$V i c ̧ o j a$ & 2,05 & 0,11 & 0,02 \\
\hline$I A C-2$ & 1,74 & 0,05 & -- \\
\hline$P L-1$ & 2,20 & 0,06 & -- \\
\hline
\end{tabular}


TABELA 6 - Determinação da atividade do inibidor de tripsina utilizando BAPA ${ }^{(*)}$ como substrato

\begin{tabular}{|c|c|c|c|}
\hline Produto & Variedáde & $\begin{array}{l}\text { UTI / mg } \\
\text { amostras }\end{array}$ & $\begin{array}{l}\text { UTI / mg } \\
\text { proteina }\end{array}$ \\
\hline \multirow{4}{*}{ Soja } & $V i c ̧ o j a$ & 29 & 69 \\
\hline & Santa Rosa & 21 & 50 \\
\hline & $I A C-2$ & 48 & 113 \\
\hline & $P L-1$ & 21 & 44 \\
\hline \multirow{4}{*}{$\begin{array}{l}\text { Farinha de } \\
\text { soja }\end{array}$} & Viçoja & 5 & 10 \\
\hline & Santa Rosa & 4 & 8 \\
\hline & $I A C-2$ & 4 & 8 \\
\hline & $P L-1$ & 6 & 12 \\
\hline \multirow{4}{*}{$\begin{array}{l}\text { Farinha de } \\
\text { tempé }\end{array}$} & Viçosa & 6 & 12 \\
\hline & Santa Rosa & 4 & 8 \\
\hline & $I A C-2$ & 9 & 18 \\
\hline & $P L-1$ & 8 & 16 \\
\hline
\end{tabular}

(*) BAPA = benzoil-DL-arginina p-nitroanilide 
TABELA 7 - Medida da radioatividade de glāndulas tireóide no grupo controle

\begin{tabular}{ccc}
$\begin{array}{c}\text { Rato } \\
\text { Nümero }\end{array}$ & $\begin{array}{c}\text { Peso } \\
(g)\end{array}$ & $\begin{array}{c}\text { Contagem média por } \\
\text { sogundos }\end{array}$ \\
\hline 1 & 98 & 23.408 \\
2 & 110 & 49.743 \\
3 & 104,5 & 33.119 \\
4 & 107 & 28.968 \\
5 & 113 & 31.741 \\
6 & 110 & 42.876 \\
7 & 112,5 & 37.032 \\
8 & 122 & 47.248 \\
9 & 127 & 59.328 \\
10 & 120 & 40.400 \\
\hline
\end{tabular}


TABELA 8 - Medida da radioatividade de glāndulas tireóide no grupo da farinha de soja, variedade Santa Rosa

\begin{tabular}{ccc}
$\begin{array}{c}\text { Rato } \\
\text { Nümero }\end{array}$ & $\begin{array}{c}\text { Peso } \\
(g)\end{array}$ & $\begin{array}{c}\text { Contagem média por } \\
30\end{array}$ \\
\hline 11 & 101 & 25.171 \\
12 & 102,5 & 39.236 \\
13 & 108,5 & 27.126 \\
14 & 107 & 36.204 \\
15 & 105 & 48.641 \\
16 & 111 & 27.802 \\
17 & 111 & 50.045 \\
18 & 111 & 21.345 \\
19 & 120 & 23.324 \\
\hline
\end{tabular}


TABELA 9 - Medida da radioatividade de glāndulas tireóide no grupo da farinha de Tempé, variedade Santa Rosa

\begin{tabular}{ccc}
\hline $\begin{array}{c}\text { Rato } \\
\text { Nümero }\end{array}$ & $\begin{array}{c}\text { Peso } \\
(g)\end{array}$ & $\begin{array}{c}\text { Contagem média por } \\
\text { 30 }\end{array}$ \\
\hline 20 & 100 & 22.171 \\
21 & 100 & 40.610 \\
22 & 115 & 29.597 \\
23 & 109 & 29.114 \\
24 & 109 & 27.479 \\
25 & 104 & 20.654 \\
26 & 107 & 35.375 \\
27 & 108 & 22.927 \\
28 & 114 & 34.962 \\
29 & 110 & 36.578 \\
\hline
\end{tabular}


TABELA 10 - Porcentagem de captação/100 g de peso de rato, nos grupos controle, farinha de soja e farinha de tempé, variedade Santa Rosa

\begin{tabular}{ccc}
\multicolumn{3}{c}{$\%$ de captação/ 100 g de rato } \\
\hline Controle & Farinha de soja & Farinha de tempé \\
\hline 13,70 & 13,59 & 11,92 \\
13,27 & 13,23 & 9,76 \\
11,44 & 11,23 & 9,70 \\
11,36 & 9,93 & 9,00 \\
9,88 & 7,35 & 7,84 \\
9,66 & 7,33 & 7,55 \\
9,30 & 7,31 & 7,39 \\
9,24 & 5,70 & 6,50 \\
7,94 & 5,64 & 6,22 \\
7,00 & $\cdots$ & 5,82 \\
\hline
\end{tabular}

TABELA 11 - Porcentagem média de captação por $100 \mathrm{~g}$ de peso de rato

\begin{tabular}{lcc}
\hline Grupos & $\%$ de captação / $100 \mathrm{~g}$ de rato & $\left.{ }^{*}\right)$ \\
\hline Controle & 10.28 a & $100 \%$ \\
Farinha de soja & 9.03 a b & $88 \%$ \\
Farinha de tempé & 8.17 b & $79 \%$ \\
\hline
\end{tabular}

(*) letras iguais não diferem estatisticamente ao nĩvel de $5 \%$ de probabilidade 
TABELA 12 - Composição em aminoācidos (mg/ $100 \mathrm{~g}$ de produto) em farinha de soja, nas variedades Santa Rosa, Viçoja, IAC-2 e PL-1

\begin{tabular}{|c|c|c|c|c|}
\hline \multirow{2}{*}{ Aminoācidos } & \multicolumn{4}{|c|}{ Farinha de soja } \\
\hline & Santa Rosa & Viçoja & IAC - 2 & $P L-1$ \\
\hline Lisina & 3.242 & 2.902 & 2.827 & 2.972 \\
\hline Histidina & 1.415 & 1.187 & 1.058 & 1.225 \\
\hline Arginina & 2.547 & 2.638 & 2.585 & 2.506 \\
\hline Acido aspārtico & 6.000 & 5.708 & 5.747 & 6.246 \\
\hline Treonina & 1.342 & 1.486 & 1.548 & 1.248 \\
\hline Serina & 1.096 & 1.315 & 1.535 & 937 \\
\hline Acido glutàmico & 8.979 & 8.233 & 8.791 & 8.070 \\
\hline Prolina & 2.041 & 2.067 & 1.896 & 2.134 \\
\hline Glicina & 2.223 & 2.238 & 2.091 & 1.856 \\
\hline Alanina & 2.158 & 2.040 & 1.971 & 2.181 \\
\hline $1 / 2$ Cistina & $\cdots$ & -- & $-\cdots$ & -- \\
\hline Valina & 1.839 & 1.790 & 2.651 & 1.988 \\
\hline Metionina & 107 & 255 & 216 & 136 \\
\hline Isoleucina & 2.434 & 2.432 & 2.390 & 2.558 \\
\hline Leucina & 4.433 & 4.552 & 4.292 & 4.725 \\
\hline Tirosina & 453 & 747 & 877 & 325 \\
\hline Fenilalanina & 2.374 & 2.423 & 2.271 & 2.525 \\
\hline
\end{tabular}


TABELA 13 - Composição em aminoācidos (mg/100 g de produto) em farinha de tempé, nas variedades Santa Rosa, Viçoja, IAC - 2 e PL - 1

\begin{tabular}{|c|c|c|c|c|}
\hline \multirow{2}{*}{ Aminoācidos } & \multicolumn{4}{|c|}{ Farinha de tempé } \\
\hline & Santa Rosa & Viçoja & $I A C-2$ & $P L-1$ \\
\hline Lisina & 3.223 & 3.854 & 3.618 & 3.028 \\
\hline Histidina & 1.288 & 1.628 & 1.220 & 1.446 \\
\hline Arginina & 2.967 & 2.705 & 2.702 & 2.524 \\
\hline Ácido aspārtico & 5.732 & 6.107 & 5.813 & 5.897 \\
\hline Treonina & 1.472 & 1.477 & 1.592 & 1.530 \\
\hline Serina & 1.414 & 1.205 & 1.537 & 1.455 \\
\hline Ácido glutāmico & 8.480 & 8.664 & 8.925 & 8.053 \\
\hline Prolina & 1.989 & 2.022 & 1.869 & 2.165 \\
\hline Glicina & 2.105 & 2.313 & 2.159 & 2.365 \\
\hline Alanina & 2.850 & 2.326 & 2.738 & 2.015 \\
\hline $1 / 2$ Cistina & -- & -- & --- & -- \\
\hline Valina & 1.822 & 2.026 & 1.818 & 1.922 \\
\hline Metionina & 256 & 148 & 220 & 191 \\
\hline Isoleucina & 2.428 & 2.516 & .2 .361 & 2.566 \\
\hline Leucina & 3.874 & 4.440 & 4.165 & 4.437 \\
\hline Tirosina & 821 & 591 & 860 & 639 \\
\hline Fenilalanina & 2.249 & 2.479 & 2.250 & 2.524 \\
\hline
\end{tabular}


TABELA 14 - Digestibilidade "in vitro" para farinha de soja e de tempé, nas variedades Santa Rosa, Viçoja, IAC - 2 e PL - 1 (\% de hidrōlise)

\begin{tabular}{lcc}
\hline \multirow{2}{*}{ Variedades } & \multicolumn{2}{c}{$\%$ Hidrōlise } \\
\cline { 2 - 3 } & Farinha de soja & Farinha de tempé \\
\hline Santa Rosa & 27,1 & 27,0 \\
Viçoja & 29,8 & 25,0 \\
IAC - 2 & 34,8 & 27,1 \\
PL- 1 & 27,9 & 30,2 \\
\hline
\end{tabular}

TABELA 15 - Digestibilidade "in vitro" para farinha de soja e de tempé, nas variedades Santa Rosa, Viçoja, IAC - 2 e PL - 1. (ug de a-aminoācidos liberados por mg de amostra)

\begin{tabular}{lcc}
\hline \multirow{2}{*}{ Variedades } & ug a-aminoācidos liberados / mg de amostra \\
\cline { 2 - 3 } & Farinha de soja & Farinha de tempé \\
\hline Santa Rosa & 81,78 & 84,83 \\
Viçoja & 82,21 & 93,60 \\
IAC - 2 & 99,26 & 89,65 \\
PL - 1 & 87,03 & 96,20 \\
\hline
\end{tabular}


6 - DISCUSSÃO DOS RESULTADOS

A Tabela 1 apresenta os resultados de proteina, obtidos pelos métodos de Kjeldahl, de Jorgensen e de Lowry, na soja descascada. Conforme pode-se observar, houve uma pequena variação nos resultados obtidos pelos dois métodos, sen do que com o de Kjeldahl, os valores foram sempre maiores daqueles obtidos pelo mētodo de Jorgensen.

Para as farinhas de soja e de tempé, pōde-se ob servar o mesmo fenómeno, isto $\bar{e}$, os valores obtidos pelo méto do de Kjeldahl mostraram-se ainda superiores.

Julgou-se conveniente estimar os valores de pro teina total pelos dois métodos anteriormente citados, desde que o de Kjeldahl é empregado universalmente em alimentos, e o de Jorgensen por ser extensivamente utilizado no Centro de Energia Nuclear da Agricultura, na medição de nitrogénio e ou 
tros elementos em plantas, sendo ainda extremamente prático e rápido, por utilizar-se de analisador automático.

A variedade que mostrou valores mais altos para proteina total foi a PL-1, considerando-se os dois métodos utilizados, seguida das variedades Viçoja e IAC-2, com valores praticamente iguais. A variedade Santa Rosa foi a que apresentou menor teor proteíco.

Vale dizer que a variedade $\mathrm{PL}-1$ caracteriza-se por possuir grãos de tamanho aproximadamente très vezes maior que as variedades comuns. Essa variedade encontra-se atual mente em fase de multiplicação das sementes.

As demais variedades foram escolhidas por serem extensivamente cultivadas no Estado de São Paulo, principalmente a variedade Santa Rosa.

Ainda na Tabela 1 , podemos observar que os valores encontrados para proteina solúvel mostraram pequena variąção entre as variedades, para um mesmo produto, sendo ligeiramente mais elevados na farinha de tempé.

Nas Tabelas 2,3 e 4 temos a composição cente simal da soja, e das farinhas de soja e de tempē.

A soja mostrou um menor teor de óleo e um maior teor de carboidratos quando comparada às farinhás de soja e de tempé, o que poderia ser explicado pelo processamento sofrido pelas $\bar{u}$ timas. As farinhas de soja e de tempē, tiveram como etapa de seu processamento a maceração por uma noite e posterior lavagem em abundāncia de água. Em consequēncia,uma 
parte dos carboidratos teria se perdido por solubilização na āgua de maceração e lavagem, ficando dessa maneira, o ōleo mais concentrado nas farinhas de soja e de tempé.

Como se pode observar pelas Tabelas 3 e 4 , 0 processo de fermentação não afetou grandemente a composição aproximada da soja. Houve um acréscimo no teor de proteina total, conforme anteriormente observado por WANG et alii (1968) e CAMARGO (1969) ; embora outros autores tenham descri to que não houve alteração na porcentagem de proteīna da soja apōs a fermentação (STEINKRAUS et azi $i, 1960$ ). Alēm disso, 0 acréscimo no teor protéico reflete o decréscimo do teor de ōleo, o qual teria sido utilizado pelo fungo para seu cresci mento, desde que o Rhizopus oligosporus é incapaz de aproveitar os carboidratos da soja (SORENSON e HESSELTINE, 1966).

0 teor de cinzas mostrou-se praticamente inalterado nas farinhas de soja e de tempè, quando comparado ao da soja, enquanto que o teor de fibra foi menor na soja do que nas farinhas.

A atividade ureātica (Tabela 5 - expressa em $\underline{u}$ nidades de variação de $\mathrm{pH}$ ), foi determinada na soja e nas res pectivas farinhas. Para a soja, a variedade que mostrou atividade mais alta foi a $P L-1$, seguida pelas variedades Viçoja, Santa Rosa e IAC-2, cuja atividade foi a menor. Esses re sultados estão bastante prōximos aos encontrados por TURATTI et alii (1979) num estudo que visou selecionar cultivares de soja para produção de leite. 
Nas farinhas de soja a atividade ureātica mostrou-se bastante diminuída, o que deveu-se, provavelmente, a tratamento térmico sofrido pelas mesmas. Segundo ALBRECHT et la $i$ i (1966) a soja macerada necessita de apenas cinco minutos de cozimento em āgua fervente para completa destruição da atividade ureātica, o que não poude ser confirmado no presente trabalho. Nas farinhas de tempé a atividade ureātica foi nula, exceto para a variedade Viçoja, que foi também a va riedade que apresentou maior valor de atividade entre as fari nhas de soja.

Na Tabela 6 estão os resultados obtidos na determinação da atividade do inibidor de tripsina (IT) utilizan do BAPA como substrato. Os resultados estão expressos em Uni dades de Tripsina Inibidas (UTI) por mg da amostra e em UTI por mg de proteína para que melhor possam ser comparados aos encontrados na literatura. Para a soja crua os valores de UTI por mg de proteína variaram de 44 a 113.

$$
\text { KAKADE et alii (1972) analisaram } 108 \text { variedades }
$$

comerciais e experimentais de soja, inicialmente ensaiadas quan to à atividade antitríptica. Com base nos valores encontra dos classificaram arbitrariamente as variedades como apresentando atividade baixa, média ou alta de IT. Segundo a classificação proposta por KAKADE et azii (1972), as variedades es tudadas no presente trabalho encontram-se na faixa de "baixa" atividade de IT $(66-121)$, sendo que duas das variedades PL-1 (44) e Santa Rosa (50), encontram-se abaixo do valor minimo en 
contrado por KAKADE.

Em 1972, WANG et alii estudaram a atividade de IT da soja fervida e fermentada por $R$. oligosporus procurando estabelecer a sua natureza. Os exitratos preparados a partir da soja fervida e fermentada mostraram maior atividade de IT do que os extratos preparados a partir da soja fervida. A partir desses estudos os autores puderam concluir que o aume to da atividade do IT na soja fermentada não era devido à sīn tese da mesma pelo fungo, pois nenhuma atividade inibitōria pó de ser medida em filtrados da cultura crescendo em meios de leite ou trigo.

Os resultados tornaram aparente que um IT ativo era liberado de uma forma inativa termoresistente pelas proteases de $R$. oligosporus. Uma vez liberado, o inibidor $\underline{e}$ ra prontamente inativado pelo calor. A atividade do IT aumen tou com o aumento do tempo de fermentação, atingido o māximo com 48 horas. Apōs esse período, a atividade decrescia, fato que póde ser explicado, pela inativação do IT por proteases do R. oligosporus.

Nesse estudo, a atividade do IT foi medida de acordo com o método de Kunitz modificado por KAKADE et a $i$ i (1969), o qual utiliza caseina como substrato.

KAKADE et azii (1974) descreveram um mētodo, o qual classificaram como mais adequado e reproduzivel para se medir a atividade do IT em produtos de soja. Por ser particu larmente indicado na determinação de produtos termo-processa- 
dos, é recomendado para uso na avaliação da destruição do IT pelo calor, em amostras de soja. Esse método inclui algumas modificações, como a extração das amostras de soja em pH de 8,4 a 10,0 ao invés de pH 7,6 , o uso de extratos não centri fugados ao invēs de centrifugados e a utilização de BAPA como substrato.

Segundo os autores, as modificações introduzidas no método, aparentemente permitem medir a atividade dos IT insolūveis e expõem os seus residuos de aminoācidos para interação com a tripsina.

Os autores vão mais longe, citando o trabalho de WANG et alii (1972) e sugerindo que pode não ser necessá rio postular a existēncia de IT ligados na soja. Durante a fermentação poderia estar ocorrendo que as proteases do $R$. ozigosporus solubilizariam os IT desnaturados pelo calor, expondo os resíduos de aminoácidos à inibição, pela interação com a tripsina.

Os resultados obtidos no presente trabalho foram similares aos anteriormente obtidos por WANG et alii (1972), pois póde-se constatar um aumento na atividade do IT na farinha de tempé para trēs, das quatro variedades de soja estudadas (Viçoja, IAC-2 e PL-1).

Como foi utilizado o mētodo de KAKADE et alii (1974) para se ensaiar a atividade do IT, pode-se supor que durante a fermentação o que ocorre é realmente a liberação dos IT ligados, pela ação das proteases do $R$. oligosporus, embo- 
ra sejam necessārios mais estudos para que se possa esclare cer se realmente o que ocorre durante a fermentação ē a liberação de IT termoresistentes ligados (inativos), ou a solubilização dos ITidesnaturados pelo calor, ou ainda, se os dois fenómenos estão ocorrendo conjuntamente.

KAKADE et azii (1972) anteriormente citado, en contraram uma larga faixa de variação nas atividades do IT e das hemaglutininas em 108 variedades e "strains" experimentais de soja. As vārias amostras de soja utilizadas nesse estudo mostraram diferenças marcantes no valor nutritivo, com um valor de PER variando de 0,75 a 1,75 , comparados a um valor de caseina de 2,5. Uma variação tão ampla daria uma grande oportunidade de se estabelecer uma correlação entre um dado pa rāmetro e o PER, se essa existisse. Apesar da evidência que implica IT e fitohemaglutininas como fatores que contribuem pa ra o pobre valor nutritivo da soja crua, nenhuma relação fi cou evidenciada nestes estudos.

Tendo em vista a falta de correlação entre a atividade do IT e O PER, o fato de haver um grau de correlação significativo entre o peso do páncreas e o PER causou sur presa, desde que é geralmente aceito que os IT são os principais responsáveis pela hipertrofia do páncreas e pobre cresci mento dos animais alimentados com soja. O método utilizado pa ra se medir a atividade de IT foi o de KAKADE et alii (1969), utilizando BAPA como substrato. Os autores sugerem que os IT poderiam estar ligados de um modo tal que não poderiam ser 
extraidos pelos solventes aquosos geralmente empregados para sua anālise. Isso poderia explicar porque os residuos insolū veis em água de soja, embora com atividade antitrípica baixa, inibem o crescimento e causam hipertrofia pancreática (GARLICH e NESHEIM, 1966). Não houve correlação também entre o PER e os aminoácidos sulfurados totais.

Temos, assim, mais um trabalho em que fica sugerida a existēncia de IT ligados, na soja.

Na Tabela 10 pode-se observar a porcentagem de captação por $100 \mathrm{~g}$ de peso de rato, comparativamente entre os grupos controle, farinha de soja e farinha de tempé. A por centagem de captação foi maior no grupo controle, variando de 7,00 à 13,70 seguindo-se o grupo farinha de $\operatorname{soja}(5,64$ à 13,59$)$ e o grupo da farinha de tempè $(5,82$ à 11,92$)$.

$\mathrm{Na}$ Tabela 11 temos a porcentagem média de captação por $100 \mathrm{~g}$ de peso de rato, comparativamente para os trēs grupos. Foi aplicado o teste "t" de Student para comparação entre duas médias. Encontrou-se que os grupos controle e farinha de soja não diferem significativamente, ao nível de $5 \%$ de probabilidade. Foi encontrada diferença significativa $(P>0,05)$ entre os grupos controle e farinha de tempé. 
Os resultados da composição em aminoācidos para as farinhas de soja e de tempé estão apresentadas nas Tabe 1 as 12 e 13.

Para o produto farinha de soja podemos notar que a composição em aminoācidos para as diversas variedades mostrou apenas ligeira variação entre os resultados. De manei ra geral as variedades assemelham-se bastante em sua composição .

Foram observadas maiores quantidades de lisina e histidina na farinha de tempē, nas variedades Viçoja, IAC-2 e PL-1.

Com relação à metionina houve um acréscimo na farinha de tempé, em relação à de soja, para as variedades San ta Rosa e PL-1.

HESSELTINE (1967) afirma que o tempè apresenta um teor de lisina e metionina decrescente na razão direta do tempo de fermentação.

CAMARGO (1969) observou os mesmos resultados para a lisina em quatro, das cinco variedades por ele estudadas, mas não para a metionina,que comportou-se de modo seme Thante ao observado no presente estudo.

A treonina teve teores maiores na farinha de tempé em trēs, das quatro variedades de soja estudadas.

Quanto à isoleucina notou-se um aumento em seu teor, na farinha de tempē, para as variedades Viçoja e PL-1. 
A leucina mostrou-se pouco alterada na farinha de tempé, embora com teores ligeiramente inferiores para todas as variedades.

- Apenas a variedade Viçoja mostrou um teor maior de fenilalanina quando comparou-se a farinha de tempē com a de soja.

De maneira geral as variedades não sofreram grande alteração no seu teor de aminoācidos essenciais por efeito da fermentação.

$\mathrm{Na}$ Tabela 14 estão apresentados os resultados da digestibilidade "in vitro" para as farinhas de soja e de tempē, medida através da porcentagem de hidrōlise.

A variedade Santa Rosa apresentou resultado praticamente igual para as farinhas de soja e de tempé.

As variedades Viçoja e IAC-2 mostraram maior porcentagem de hidrólise na farinha de soja.

Apenas a variedade $\mathrm{PL}-1$ apresentou maior por centagem de hidrōlise na farinha de tempé, quando comparada à farinha de soja.

Na Tabela 15 a digestibilidade "in vitro" é da da pela quantidade de aminoācidos liberados por mg de amostra. Apenas a variedade IAC-2 apresentou maior teor de aminoácidos na farinha de soja. As demais variedades mostraram liberação de teores mais elevados na farinha de tempé, em comparação com a farinha de soja. 
Sendo o fungo utilizado para o preparo do tempé, um fungo proteolitico, esperava-se que a digestibilidade da farinha de tempé fosse maior do que a da farinha de soja, desde que ${ }^{i} \bar{e}$ sobejamente conhecida a natureza refratāria das proteinas da soja.

Entretanto, os resultados obtidos através do método utilizado para medir a digestibilidade "in vitro" das farinhas sugere não haver praticamente diferença entre os tra tamentos. 


\section{7 - CONCLUSÕES}

a - A maceração elimina parte dos sōlidos solūveis da soja, notadamente os carboidratos.

b - 0 processo de fermentação não altera grandemente a composição centesimal da farinha de tempé, quando comparada à farinha de soja.

c - 0 tratamento tērmico sofrido pelas farinhas è suficiente para inativar a urease em no minimo, $94,6 \%$.

d - As variedades de soja estudadas classificam-se na faixa de "baixa" atividade do inibidor de tripsina, sendo que duas das variedades estudadas PL- 1 e Santa Rosa, estão abaixo do valor mínimo encontrado por KAKADE et aliz $(1972)$. 
e - Pelos resultados obtidos com a determinação da atividade do inibidor de tripsina, para as farinhas de soja e de tempé, não foi possível afirmar se durante a fermentação o que ocorre è a liberação dos IT termoresistentes ligados (inativos), ou a solubilização dos IT desnaturados pe lo calor, ou ainda, se os fenōmenos estão ocorrendo con juntamente.

$f$ - Existe um fator presente na farinha de tempé, capaz de diminuir a captação de iodo pela glàndula tireóide de ra tos, 24 horas apōs sua adminstração

g - A composição de aminoācidos mostrou-se praticamente sem alterações nos dois produtos estudados.

h - Embora algumas variedades tenham apresentado maior liberação de aminoācidos na farinha de tempé, a porcentagem de hidrōlise foi bastante semelhante entre os dois produ tos estudados. 


\section{8 - LITERATURA CITADA}

AKESON, W. R. e M. A. STAHMAN, 1964. A pepsin pancreatin digest index of protein digestibility evaluation. J.Nutr., Philadelphia, 83: 257-261.

ALBRECHT, W. J. ; C. G. MUSTAKAS e J. E. MCGHEE, 1966. Rate studies on atmospheric steaming and immersion cooking of soubeans. Cereal Chemistry, Minneapolis, 43(4): 400-407.

AMERICAN ASSOCIATION OF CEREAL CHEMISTS, 1969. Approved Methods of the American Association of Cereal Chemists. St. Paul, AACC.

ASSOCIATION OF OFFICIAL AGRICULTURAL CHEMISTS, 1970. Official Methods of Analysis. Ed. by William Howitz, 11. ed. Washington, AOAC. $1015 \mathrm{p}$.

BECK, R. N., 1958. Soy flour and fecal tyroxine loss in rats. Endocrinology, Springfield, 62: 587-592. 
BLOCK, R. J. e R. H. MANDL, 1961. The curative action of iodine on soybean goiter and the changes in the distribu tion of iodoamino acids in the serum and in thyroid gland digests. Arch. Biochem., New York, 93: 15-24.

BORCHERS, R. A. ; C. W. ACKERSON E F. E. MUSSEHL, 1948. Trypsin inhibitor VI. Effect of various heating periods on the growth promoting value of soybean oil meal for chicks. Poultry Science, Columbus, 27: 601-604.

BUCK, F. F. ; M. BIER e F. F. NORD, 1962. Some properties of human trypsin. Arch. Biochem. Biophys., 98: 528-530.

CAMARGO, R., 1969. Contribuição ao estudo de dois alimentos orientais - o tempeh e o tofu - obtidos da soja (Glycine $\max$ (L.) Merril). (Tese de Livre-Docēncia), Piracicaba, SP. $88 \mathrm{p}$.

COATES, M. E. ; D. HEWITT e P. GOLOB, 1970. British J. Nutr. 24: 213, citado por RACZS, J. M., 1974. Biological and physiological factors in soybeans. J.Am. 0il Chem Soc., Chicago, 5l: 161.A-174.A.

COSTA, S. I. ; D. G. QUAST; V. A. MORETTI ; W. L. CANTO e R. V. COBBE, 1976. O emprego da soja na alimentação humana. Boletim do ITAL, Campinas, 46: 1-24.

DIEMAIR, W., 1963. Laboratoriumsbuch für den Lebensmittel1chemiker, 8 -Auflage. Dresden und Leipzig, Verlag von Theodor Steinkopff, p. 28-29 
FEENEY, R. E. ; G. E. MEANS e J. C. BIGLER, 1969. Inhibition of human trypsin, plasmin and trombin by naturally occurring inhibitors of proteolytic enzimes. J.Biol. Chem. Baltimore, 244: 1957-1960.

FIELDS, R., 1972. The rapid determination of aminogroups with TNBS. Methods in Enzimology, XXV, part. 6: 464-468.

FILISETTI, T. M. C. C., 1977. Efeito da ingestão de derivados da soja (Glycine max). sobre a tireóide de ratos. Estu do com o emprego de iodo radioativo. (Tese de Mestrado), S.P., 82 P.

GARLICH, J. D. e M. C. NESHEIM, 1966. Relationship of fractions of soybeans and a crystalline soybean meal to chicks. J. Nutrition, Philadelphia, 88: 100-110.

GERTLER, A. ; Y. BIRK e A. BONDI, 1967. A comparative study of the nutritional and physiological significance of pure soybean trypsin inhibitors and ethanol-extracted soybean meals in chicks and rats. J. Nutrition, Philadelphia,.91: 358-370.

HACKLER, L. R. ; K. H. STEINKRAUS; J. P. VAN BUREN e D. B. HAND, 1964. Studies on the utilization of tempeh protein by weanling rats. J. Nutrition, Philadelphia, 82: 452456 .

HAINES, P. C. e R. C. LYMAN, 1961. Relationship of pancreatic enzyme secretion to growth inhibition in rats fed soybean trypsin inhibitor. J. Nutrition, Philadelphia, 74 : $445-452$. 
HALVERSON, A. W. ; ZEPPLIN, M. e E. B. HART, 1949. Relation of iodine to the goitrogenic properties of soybeans. J. Nutrition, Philadelphia, 38: 115-129.

HESSELTINE, C. W. ; R. CAMARGO e J.J. RACKIS, 1963. A mould inhibitor in soybeans. Nature, London, 200(4912): $1226-$ 1227 .

HESSELTINE, C. W., 1967. A millenium of fungi, food and fermentation. Mycologia, New York, 57(2): 149-197.

HYDOWITZ, J. D., 1960. Occurrence of goiter in an infant on soy diet. New Engl. J. Med., Boston, 262: 351-353.

JORGENSEN, S. S., s/d. Some Methods Used for Routine Chemical Analysis, Division of Basic Sciences, Piracicaba, CENA (Laboratoy Manual).

KAKADE, M. L. ; M. SIMONS e I. E. LIENER, 1969. An evalua tion of natural vs. synthetic substrats for measuring the anti.tryptic activity of soybean samples. Cereal Chemistry. st. Paul., 46: 518-526.

KAKADE, M. L. ; N. R. SIMONS ; I. E. LIENER E J. W. LAMBERT, 1972. Biochemical and nutritional assesment of different varieties of soybenas. J.Agr. Food Chem., Washington, 20(7): $87-90$.

KAKADE, M. L. ; J. J. RACKIS; J. E. MCGREE E G. PUSKI, 1974. Determinations of tripsin inhibitor of soy products. A collaborative analysis of an improved procedure. Cereal Chemistry, St. Paut., 51(3): 376-382. 
KLOSE, A. A. ; B. HILL e H. L. FEVOLD, 1948. Food Tech., 2 201, citado por RACKIS, J. J., 1974. Biological and physiological factors in soybeans. J.Amer. $0 i l$ Chem. Soc., Chicago, 51: 161.A-174.A.

KONIJN, A. M. ; S. EDELSTEIN e K. GUGGEHEIM, 1972. Separa tion of a thyroid-active fraction from unheated soya bean flour. J.Sci. Food Agric., London, 23: 549-555.

KONIJN, A. M. ; B. GERSHON e K. GUGGEHEIM, 1973. Further pu rification and mode of action of a goitrogenic material from a soybean flour. J.Nutr., Philadelphia, 103: 278383 .

LEWIS, J. H. e F. H. L. TAYLOR, 1947. Citado por RACKIS, J. J., 1974. Biological and physiological factors in soy beans. J.Am. 0il Chem. Soc., Chicago, 51: 161.A-174.A.

LIENER, I. E., 1955. The photometric determination of the hemaglutinating activity of soyin and crude soybean extracts. Arch. Bioch. Biophys, New York, 54: 223-231.

LIENER, I. E. e M. L. KAKADE, 1969. Protease inhibitors. In: I. E. LIENER, ed. Toxic Constituents of Plant Foodstuffs.

LOWRY, O. H. ; N. J. ROSEBROUGH ; A. L. FARR E N. J. RANDALL 1951. Protein measurement with the folin phenol reagent. J.Biol. Chem., Baltimore, 193: 265-275.

MCCARRISON, R., 1933. The goitrogenic action of soybean and ground-nut. Indian J. Med. Res., New Delhi, 21: $179-181$. 
MURATA, K. ; H. IKEHATA e T. MYIAMOTO, 1967. Studies on the nutritional value of tempeh. J.Food Sci., Chicago, 32: 580-586.

NORDSIEK, F. W., 1962. Effects of added casein on goitrogenic action of different dietary levels of soybeans. Proc. Soc. Exp. Biol., New York, 110: 417-420.

PINCHERA, A. ; M. H. MACGILLIVRAY ; J. D. GRAWFORD e A. G. FREEMAN, 1965. Thyroid refractoriness in an athyreotic cretin fed soybean formula. New Engl. J. Med., Boston, 273: $83-87$.

RACKIS, J. J., 1965. Physiological properties of soybean trypsin inhitibors and their relationships to pancreatic hipertrophy and growth inhitibion of rats. Fed. Proceedings, Washington, 24: 1488-1493.

RACKIS, J. J., 1966. Soybeans trypsin inhibitors: their inactivation during meal processing. Food Tech., Chicago, 20: $1482-1484$.

RACKIS, J. J., 1974. Biological and physiological factors in soybeans. J.Am. 0il Chem. Soc., Chicago, 20: 161.A-174.A.

SAMBETH, W. ; M. C. NESHEIM e J. A. SERAFIN, 1967. Separa tion of soybean whey into fractions with different biologi cal activities for chicks and rats. J. Nutr.. Philadel phia, 92: $479-490$.

SHARPLESS, G.R. ; J. PEARSONS e G. S. PRATO, 1939. Production of goiter in rats with raw and treated soybean flour. J. Nutr., Philadelphia, 17: 454-555. 
SHEPARD, T. H. ; G. E. PYNE; J. F. KIRSCHVINK e M. C. MCLEAN, 1960. Soybean goiter: report of three cases. New Engl. J.Med., Boston, 262: 1099-1103.

SMITH, K. A. ; P. A. BELTER e R. L. ANDERSON, 1956. Urease activity in soybean meal products. J.Am. $0 i 1$ Chem. Soc., Chicago, 8: $360-363$.

SMITH, K. A. ; J. J. RACKIS ; L. L. MCKINNEY; D. J. ROBBINS e A. N. BOOTH, 1964. Feedstuffs, 36: 46, citado por RACKIS,J. J., 1974. Biological and physiological factors in soybeans. J.Am. 0i1 Chem. Soc., 51: 161.A-174.A.

SOCOLOW, E. L. e M. SUZUKI, 1964. Possible goitrogenic effects of selected japanese foods. J. Nutr., Philadelphia, 83: $20-26$.

SORENSON, W. G. e C. W. HESSELTINE, 1966. Carbon and nitrogen utilization by Rhizopus origosporus. Mycologia, New York, 58: 681-689.

SPIEGEL, M. R., 1967. Estatistica. Rio de Janeiro. Livro Técnico, $580 \mathrm{p}$.

STEINKRAUS, S. K. ; Y. B. HWA; J. P. VAN BUREN;M. I. PROVI DENTI e D. B. HAND, 1960. Studies on tempeh - an Indonesian fermented soybean food. Food Research, Champaign, 25(6): $777-788$.

TURATTI, J.M. ; A. M. SALLES;L.C. SANTOS;F. E. M. MORI e I. E. FIGUEIREDO, 1979. Estudos preliminares com culti vares de soja para produção de leite. Bol. ITAL, Campi nas, 16 $(3): 289-305$. 
VAN MIDDLESWORTH, L., 1957. Thyroxine excretion, a possible cause of goiter. Endocrinology, Springfield, 61: 570573 .

VAN WIK, J. J. ; M. B. ARNOLD; J. WYNN E F. PEPPER, 1959. The effects of $s$ soybean product on thyroid function in humans. Pediatrics, Springfield, 24: 752-760.

WANG, H. L. ; D. I. RUTTLE e C. W. HESSELTINE, 1968. Brotein quality of wheat and soybean after Rhizopus oligosporus fermentation. J.Nutr., Philadelphia, 96: 109-1l4.

WANG, H. L. ; VESPA, J. B. e C. W. HESSELTINE. 1972. Release of bound trypsin inhibitor in soybean by Rhizopus oligosporus. J.Nutrienties. Philadelphia, 102: 1495-1500.

WILGUS, J.R. ; H. S. GASSNER ; A. R. PATTON e R. G. GUSTAVSON 1941. The goitrogencity of sołeans. J.Nutr., Philadel phia, 22: 43-52. 